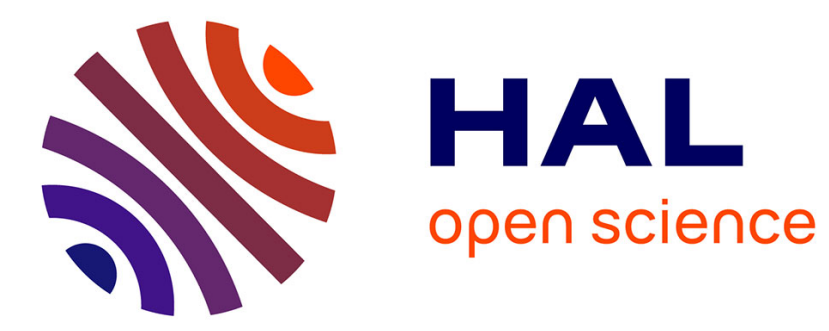

\title{
Some comments on the effect of uranium zonation on fission track dating by LA-ICP-MS
}

\author{
Nathan Cogné, Kerry Gallagher
}

\section{To cite this version:}

Nathan Cogné, Kerry Gallagher. Some comments on the effect of uranium zonation on fission track dating by LA-ICP-MS. Chemical Geology, 2021, 573, pp.120226. 10.1016/j.chemgeo.2021.120226 . insu-03196930

\section{HAL Id: insu-03196930 https://hal-insu.archives-ouvertes.fr/insu-03196930}

Submitted on 13 Apr 2021

HAL is a multi-disciplinary open access archive for the deposit and dissemination of scientific research documents, whether they are published or not. The documents may come from teaching and research institutions in France or abroad, or from public or private research centers.
L'archive ouverte pluridisciplinaire $\mathbf{H A L}$, est destinée au dépôt et à la diffusion de documents scientifiques de niveau recherche, publiés ou non, émanant des établissements d'enseignement et de recherche français ou étrangers, des laboratoires publics ou privés. 


\section{Some comments on the effect of uranium zonation on fission track dating by}

\section{LA-ICP-MS}

Nathan Cogné*1 and Kerry Gallagher ${ }^{1}$

${ }^{1}$ Univ Rennes, CNRS, Géosciences Rennes, UMR 6118, 35000 Rennes, France

*corresponding author: nathan.cogne@univ-rennes1.fr

\section{Abstract}

The use of LA-ICP-MS for uranium determination in the fission track dating technique is becoming increasingly popular because of several advantages over the classical external detector method and a variety of analytical and statistical protocols have been developed. However, two important issues remain unresolved in the context of the LA-ICP-MS approach (i) how to best deal with low track density $\left(\rho_{s}\right)$ samples, and (ii) does a correlation between age and uranium content (or eU) reflect an annealing dependence or not? To assess the impact of the analytical methodology on these issues, we compare the multi-spot and more classical single spot methods on samples of known ages, variably zoned and / or with low track densities. To make the comparison we use an approach, implemented in a Python script, that randomly samples our multi-spot ICP-MS data to choose a single $U$ measurement per grain, simulating the single spot approach. We then calculate the central age, $\mathrm{p}\left(\chi^{2}\right)$ and dispersion of the simulated single spot analysis and repeat this 2000 times. Our results show that the multi-spot approach is robust for low $\rho_{s}$ and zoned samples, yielding both accurate and precise results without over-dispersion. Additionally, our random sampling approach shows that a single spot measurement can induce an overdispersion coupled to a relationship between single grain age and 
$\mathrm{U}$ content. This is at least partly attributable to zonation that creates a mismatch between the $U$ in the counted area and the spot-measured $U$. Therefore, we recommend that if over-dispersion is observed for basement samples, when one typically expects a single age population, then multiple spot analysis should be carried out to assess if the excess dispersion is linked to undetected zoning and / or laser spot misplacement rather than to $U$ dependent annealing behaviour.

Keywords: Fission track dating; LA-ICP-MS; single grain age dispersion; Uranium zonation

\section{1- Introduction}

Fission track dating is a thermochronological method based on the creation of defects (tracks) during the spontaneous fission of ${ }^{238} \mathrm{U}$. These latent tracks can be revealed with an appropriate chemical etching protocol and then observed under an optical microscope (Price and Walker, 1962). As part of the analytical procedure, it is necessary to estimate the uranium $(U)$ content of the mineral being dated. Towards the end of the $20^{\text {th }}$ century a consensus on the $\zeta$ (zeta) calibration approach and the external detector method (EDM) was reached (Hurford and Green, 1983, Hurford, 1990). The EDM protocol consists of irradiating the targeted mineral to induce fission of ${ }^{235} \mathrm{U}$ providing an indirect measure of ${ }^{238} \mathrm{U}$ when calibrated against a dosimeter or standard glass of known $U$ concentration. The mineral being dated is etched prior to irradiation and then placed in intimate contact with a low-U detector, usually a muscovite sheet. After irradiation the induced tracks are then revealed by etching the detector. The $\zeta$ approach regroups the thermal flux of the neutron irradiation and the fission decay constant, historically often considered to be not well defined, in a single 
51 calibration factor, $\zeta$ (see Hurford and Green, 1983 for more details). This factor is estimated by analyzing samples of known ages and recasting the age equation in terms of $\zeta$ as an unknown. Despite the advantages of this coupled approach, the EDM suffers from some setbacks including (i) the need for three different counts of tracks: in the mineral, the detector and the dosimeter and (ii) the manipulation of hazardous hydrofluoric acid to etch the muscovite detector (iii) increasingly difficult access to low energy neutron irradiation to induce fission tracks in the detector.

Therefore, during the early 2000's researchers explored the use of LA-ICP-MS to determine $U$ concentration of the mineral to be dated. Hasebe et al. (2004) demonstrated the feasibility of this technique. During the past decade several protocols have been developed for FT dating, mainly on the calcium-phosphate mineral, apatite. Building on Donelick et al., 2005 and Donelick and Chew, 2012, Cogné et al., 2020 proposed a $\zeta$-based protocol, while other authors have suggested using an absolute approach (e.g. De Grave et al., 2012; Soares et al., 2014, Gleadow et al., 2015). Importantly, statistical methods for processing the LA-ICP-MS data have been developed recently (Vermeesch, 2017, 2019) and we incorporate these into the analysis we present later.

It has also been shown that laser spot ablation can also produce accurate U$\mathrm{Pb}$ and trace element data simultaneously during the analysis required for AFT data (e.g. Chew and Donelick, 2012, Chew et al., 2016, Cogné et al., 2020). This is a big advantage of the LA-ICP-MS method as the additional data can help to better understand the AFT age data in both the analytical and geological contexts. In contrast to the EDM method, application of the LA-ICP-MS approach can be problematic in case of samples zoned in $U$. The EDM method produces an approximate map of $U$ concentration and typically both spontaneous and induced 
tracks are counted on the same area, implicitly allowing for zoning to some degree. For LA-ICP-MS only spontaneous tracks are counted and typically only a limited part of the counted area is analyzed for $U$ concentration by the ablation spot. Although zonation in the $z$ axis direction can be dealt with (Chew and Donelick, 2012, Cogné et al., 2020), in-plane or horizontal zonation is less readily resolved by the routine (i.e. single ablation spot) methods used in AFT dating. For samples with high spontaneous track densities $\left(\rho_{s}\right)$ the zonation is often visible in the spatial distribution of spontaneous tracks. In that case, an analyst can select a counting area that is unzoned and/or close to the shape and size of the laser spot. However, dealing with potential zoning becomes more problematic for samples with low $\rho_{\mathrm{s}}$. If an analyst selects a small area that mimics the laser spot then the number of counted tracks is likely to be low and the uncertainty on a single grain age (SGA) increases. Two methods have been proposed to overcome the zoning/low $\rho_{\mathrm{s}}$ issue, both requiring counting tracks on a large area. Vermeesch (2017) suggested using multiple laser spots (multi-spot) to improve understanding of the $U$ distribution spatially. More recently, Ansberque et al. (2020) proposed mapping the entire grain with a raster. Both approaches, however, are time consuming and more expensive compared to single spot analysis. Ideally, they then should be used only when necessary for example if a large SGA dispersion is detected.

A second issue with the use of LA-ICP-MS is the commonly larger dispersion of SGA compared to those from EDM. For example, Ketcham et al. (2018) reported an interlaboratory experiment which consisted of blind dating two samples S1 and S2. Of thirteen analysts, five used LA-ICP-MS and eight used EDM. The mean dispersion for EDM was $2.5 \%$ for $\mathrm{S} 1$ and $2.1 \%$ for S2 while for LA-ICP-MS the mean dispersion was $17.3 \%$ for S1 and $10.4 \%$ for S2. Regarding the canonical $\chi^{2}$ test, that 
101 is used to assess the possibility of single versus multiple or over-dispersed age 102 populations in a given sample, none of the EDM data sets failed the test $\left(p\left(\chi^{2}\right)<\right.$ 103 0.05) while three out of five of LA-ICP-MS dataset failed for S1 and two out of five for 104 S2. Such over-dispersion can be problematic because it could be used to infer multiple age populations that do not really exist. In this context some authors have suggested that the dispersion in SGA can be explained by the $U$ content, or eU content $(\mathrm{eU}=[\mathrm{U}]+0.235[\mathrm{Th}])$ (e.g. Fernie et al., 2018; McDannell et al., 2019). These authors demonstrated that the SGA from LA-ICP-MS are often older for lower U grains and McDannell et al. (2019) argue for a radiation damage control on annealing. Previously, Hendricks and Redfield (2005) proposed a similar $\alpha$-radiationenhanced-annealing (REA) for EDM SGA data from the Fennoscandian shield. However, Kohn et al. (2009) reconsidered the question using a different set of data from various cratonic settings and concluded that there was no link between eU and AFT age. This question is perhaps still open for the EDM, but has also become topical for the LA-ICP-MS approach in the light of new datasets.

In this contribution we aim to test the multiple spot approach of Vermeesch (2017) on samples of known age and also zoned and/or low $\rho_{\mathrm{s}}$ samples. We aim to assess if this approach leads to decreased SGA dispersion in case of undetected zonation. The second objective is to investigate if an inferred relationship between $U$ content and SGAs could be explained in part by such zonation.

\section{2- Samples and Methods}

\subsection{Samples}

We selected two apatite age standards: Fish Canyon Tuff (FCT $-28.1 \pm 0.1$ Ma, Boenhnke and Harrison, 2014) and Mount Dromedary (MtDrom - 98.5 $\pm 0.5 \mathrm{Ma}$, 
McDougall and Wellman, 2011) because both are well characterized in terms of their

127 AFT ages, often being used as age standards. We selected eight additional samples,

128 all previously dated with AFT (EDM and/or LA-ICP-MS) from crystalline basement

129 from various tectonic settings (high and low exhumation rate) with known (because of 130 high track densities) or possible (unidentifiable because of low track densities) $U$ 131 zoning, see Table 1 for details. Because all samples were previously dated, we can 132 test the accuracy of the multi-spot approach. The sample M1 was chosen because of 133 its visible zonation due to the high track density. However, this sample is treated as if 134 the zonation was not visible (i.e. spots for the multi-spot approach were randomly 135 positioned on the counted area). The motivation for doing this was to simulate what 136 could happen (increasing dispersion, SGA-U content correlation) when one has not 137 detected the zonation. The other samples were chosen because of the possible 138 zonation and / or low track density to assess how an unknown zonation can affect the results of single versus multi-spot analysis.

\subsection{Methods}

All analyses were performed at the GeOHeLiS analytical platform (Univ.

143 Rennes, France) and follow the protocol of Cogné et al. (2020). All samples were 144 mounted in a $1.5 \mathrm{~mm}$ thick epoxy disc. The apatites were etched using a $5.5 \mathrm{M}$ $145 \mathrm{HNO} 3$ at $21^{\circ} \mathrm{C}$ for 20 s. The grain mounting and etching are similar to the protocol 146 described by Donelick et al. (2005). Spontaneous fission track counting was carried 147 out using a Zeiss Axiolmage M1 equipped with an automated stage system using 148 TrackWorks software at a magnification of $1000 \times$. The U/Ca ratios, determined using 149 an ESI NWR193UC Excimer laser coupled to an Agilent 7700x Q-ICP-MS, were 150 used to calculate the ages (see Cogné et al., 2020 for details on the protocol). The 
151 laser spot size was $30 \mu \mathrm{m}$ with a repetition rate of $5 \mathrm{~Hz}$ and a fluence of $4 \mathrm{~J} / \mathrm{cm}^{2}$. All

152 instrumental conditions are summarized in the supplementary table S1.

For each grain the spontaneous track counting area was chosen to be large

154 enough to accommodate three to four ablation spots when possible. For the sample M1 a smaller area was also delimited and counted to compare a "guided" single spot approach with the multi-spot approach on the same grains. Guided here means that the counted area is close in size and shape to the ablation spot and selected from a region considered not too zoned, the low zonation being assessed on the basis of the reasonably high and uniform track density (see Figure 1). For sample HIM 622/244 the whole grain area was counted irrespective of the size of the grain. We did this because the track densities in this sample are so low that not taking into account the whole area of the grains would tend to increase the estimated density and lead to older SGA. The multi-spot approach of Vermeesch (2017) consists of calculating the mean and variance $\mathrm{U} / \mathrm{Ca}$ ratio from individual spots. We used IsoplotR (Vermeesch, 2018), in which the approach is implemented, to calculate central age, dispersion and $\mathrm{p}(\chi 2)$ for each sample. Pooled ages and associated uncertainties are calculated using the spreadsheet discussed in Cogné et al. (2020) with single grain mean U/Ca ratios and associated uncertainties calculated according to Vermeesch (2017).

Routinely, the $U$ analysis for LA-ICP-MS FT dating is performed using only one spot (e.g. Cogné et al., 2014, 2016). As previously explained, application of this protocol to low $\rho_{\mathrm{s}}$ samples is problematic as it is not always obvious where to best put the small ablation spot in the larger counted area. To simulate an effectively random choice of ablation position, we used random sampling of multi-spot $\mathrm{U} / \mathrm{Ca}$ measurements to select one value for each grain and then calculate the equivalent central age, dispersion and $p(\chi 2)$ of the sample. We repeated this sampling 2000 
176 times, the goal being to compare what a standard single spot ablation approach

177 would have yield to the multi-spot approach in terms of accuracy and precision of the 178 central age and the dispersion of the SGA.

179

180

181

182

183

184

185

\section{3- Results}

The results are summarized in Table 2 and single grain data are provided as supplementary data (Table S2). All multi-spot samples yielded similar pooled and central ages and have $p\left(\chi^{2}\right)>0.05$. A large part of the samples actually exhibits high p-value (>0.8) which might indicate an overestimation of the SGA uncertainty. The low dispersion of SGA indicates a high probability of single age population, as it is expected for bedrock sample. Guided single spot results for sample M1 also show $p\left(\chi^{2}\right)>0.05$, although the dispersion of the SGA is larger than for multi-spot results (Figure $1 \mathrm{~b}$ and $1 \mathrm{c}$ ). All ages are indistinguishable at the $2 \sigma$ level of the published ages except for HIM622/244 (Table 1, Figure 2). For that sample, the EDM reference age is $0.03 \pm 0.04 \mathrm{Ma}$ (Treloar et al., 2000), somewhat younger than the age in the present study. However, our age is similar to that given by Ansberque et al. (2020) also with LA-ICP-MS. We will discuss this difference in more detail below. The relative central age uncertainties (presented as $2 \sigma$ throughout the text) range from 5$7 \%$ for 'normal' to high track density samples (MtDrom, FC1) to $25-33 \%$ for very low track density samples (SG19, HIM 622/244), which is in the precision range of fission track dating. The radial plots for the multi-spot data are shown on Figure 3, except for sample M1 that is presented in detail on Figure 1. Single grain dots are color-coded according to their mean U/Ca content.

To assess the degree of grain U/Ca zonation $(Z)$ for a given sample we calculate the relative uncertainty of the mean $\mathrm{U} / \mathrm{Ca}$ ratio for each grain as calculated 
201

202

203

204

205

206

207

208

209

210

211

212

213

by Vermeesch (2017), and then we take the average and standard deviation of that ratio over all grains (equation 1).

$$
Z=\frac{1}{N} \sum_{i=1}^{N}\left(\frac{\sigma_{U / C a_{i}}}{\overline{U / C a_{\iota}}}\right)
$$

where $\mathrm{N}$ is the number of grains of the sample. If this average is low, then the intra grain zonation is rather limited, even if the $U$ concentrations in each grain may be very different. Conversely if this value is high, this indicates a high proportion of zoned grains in the sample.

In figure 4 we summarise the results from the 2000 random draws of one of the multi-spot U/Ca ratios per grain. For highly zoned samples (M1, SG9, HIM622/244), most of the draws lead to a large SGA dispersion (averaging $>40 \%$ ), involving failure of the $\chi^{2}$ test $80-100 \%$ of the time. In contrast, samples with little zoning (FCT, SG10, SG19, FC1) have low dispersion, rarely failing the $\chi^{2}$ test $(0-10 \%$ of the time). Two moderately zoned samples ( $\mathrm{Pb} 1$ and $\mathrm{RM} 13)$ show intermediate behaviour ( $\chi^{2}$ test $25-60 \%$ failure rate). An exception to this trend is the relatively uniform MtDrom sample with draws that often ( $60 \%)$ fail the $\chi^{2}$ test. This case will be further discussed below.

Figure 5 shows the radial plots for a single random draw for each sample, except sample M1 that is already presented in detail on Figure 1. Single grain ages are color-coded according to the U/Ca content. This figure shows that, even for less zoned samples (e.g. FCT, SG10, SG19, FC1), the dispersion of random draw single spot SGA increases relative to the multi-spot data. The increased dispersion will potentially lead to failure of the $\chi^{2}$ test. This dispersion is also associated with a generally more pronounced apparent inverse correlation of the SGA with $U$ content 
224 (see supplementary material (Fig. S3) for plots of eU $v$ age for the multi-spot and 225 single spot data).

\section{4- Discussion}

\subsection{Age accuracy and precision with multi-spot approach}

The central and pooled ages estimated using the multi-spot approach reproduce the published literature ages well (Table 1 and Fig. 2), except the EDM age of HIM622/244 (Treloar et al., 2000) which is discussed below. The precision of SGAs using the multi-spot approach tends to be lower than when using a single spot (see for example guided single spot vs multi-spot data for M1, Fig. 1b and 1c). This

234 effect seems to be larger for more highly zoned samples (compare Fig. 3 and 5), 235 such that the precision on SGA with multi-spot can half that when using a single spot. 236 For the single spot approach, the uncertainty on the U/Ca ratio comes directly from a 237 single ICP-MS measurement, while for the multi-spot approach it is calculated from 238 the different measurements of $\mathrm{U} / \mathrm{Ca}$ on the same grain. Consequently, the more 239 zoned a sample is, the more variability of the individual U/Ca will increase, as will the overall variance. Indeed, where the uncertainty $(2 \sigma)$ of single U/Ca measurement 241 was usually ca. $7 \%$ during this study, the uncertainty of mean U/Ca for a grain rises 242 to ca $60-70 \%$ for zoned samples or even $130 \%$ for HIM622/244. Therefore, while the 243 multi-spot approach gives a better understanding of the U/Ca distribution, the 244 resulting precision decreases strongly if the zonation is important. The decreasing 245 precision on the U/Ca ratio may induce an under-dispersion of the age data, leading 246 in turn to a relatively high p-value. This effect is potentially due to an over estimation 247 of $U$ variability because we only use few measurements per grains (i.e. 2 to 4 spots). 
248 In any case the under dispersion remains minor and we thus suggest that this does 249 not preclude the use of the multi-spot approach.

In a low $\rho_{s}$ sample it is not possible to infer the zonation before ablation.

251 Therefore, reliably determining the central age of a sample using a single spot 252 approach would require using a counting area that mimics exactly the ablation spot. 253 For example, a sample with $\rho_{\mathrm{s}}$ ca. $1 \mathrm{e} 5 \mathrm{tr} / \mathrm{cm}^{2}$, a precision of U/Ca measurement of $2547 \%$ and a precision of zeta of $1.5 \%$ (typical values in this study), 30 grains with a spot 255 of $30 \mu \mathrm{m}$ diameter (typical number of counted grains and spot size) would result in a 256 central age uncertainty of ca. $45 \%$. With a $\rho_{\mathrm{s}}$ of $1 \mathrm{e} 4 \mathrm{tr} / \mathrm{cm}^{2}$ the uncertainty rises to ca. $257140 \%$. Our samples with comparable $\rho_{\mathrm{s}}$ have central age uncertainties of ca. 15 to $25825 \%$ using the multi-spot approach. To achieve similar precision with a single spot 259 approach, one would need to ablate ca. 100 to 1000 grains, for $\rho_{s}$ of 1 e 5 and 1 e4 $260 \mathrm{tr} / \mathrm{cm}^{2}$ respectively, which is time-consuming, and in turn could increase the risk of 261 over-dispersion by increasing the probability of using outliers grains.

It is thus preferable to use the multi-spot approach than the single spot approach for low $\rho_{\mathrm{s}}$ samples. In addition to delivering a better understanding of $U$ 264 distribution in each grain, it is more efficient in that we obtain a more reliable and 265 precise age. In high $\rho_{\mathrm{s}}$ samples, however, one might prefer to use a guided single 266 spot approach instead of using multi-spot as it is more precise, even with a lower 267 number of tracks counted, and faster, as demonstrated in the comparison for our M1 268 sample.

HIM622/244 is the only sample where we do not adequately reproduce the

270 EDM central age. However, our age is similar to that determined by Ansberque et al. 271 (2020), also obtained with LA-ICP-MS. These authors stated that the reasons for 272 discrepancy remain unclear. While we agree with that statement, we suggest two 
273 possible reasons to partly explain the older ages obtained using LA-ICP-MS. Firstly, 274 the zero track grains represent half of the grains counted in this sample. The Cogné 275 et al. (2020) protocol, following Vermeesch (2017), does not attribute a zero Ma age to zero spontaneous track grains, while this was most likely the case for Treloar et al.

277 (2000). If we assign a zero age to these zero track grains then the central age falls to $2780.86 \pm 0.76 \mathrm{Ma}$; closer, but still different, to the EDM age, and closer to our pooled age of $0.45 \pm 0.21 \mathrm{Ma}$ (Table 1). Secondly it is possible that we selected more grains with tracks than Treloar et al. (2000), which can explain the older age we obtain or equivalently Treloar et al, (2000) selected more zero track grains. The actual number of zero track grains clearly impacts the final central or pooled ages. A random draw of 20 grains from the 50 actually measured in this study, again repeated 2000 times, and using a zero Ma age for the zero track grains reproduced the central age of Treloar et al. (2000) ca. $13 \%$ of the time. Therefore, irrespective of this single discrepant age, we reiterate that the central ages determined in this study using the multi-spot approach agree well with the vast majority of published ages.

\subsection{The effects of $U$ zonation on LA-ICP-MS FT dating} In the examples of our random draws (Fig. 5), we see that high-U grains (red grains (yellow colours). Some correlation of $U$ and SGA is expected based on 293 statistical arguments (Pearson, 1896). The fission track age equation can be approximated to a good precision by a linear equation in which the age (t) is proportional to the ratio of $\rho$ s to $U$ concentration following (eq.5 of Vermeesch, 2017):

$$
t=\frac{1}{\lambda_{d}} \ln \left(1+\frac{\lambda_{d}}{\lambda_{f}} \frac{2 N_{S}}{\left[{ }^{238} U\right] A_{S} L q}\right) \approx \frac{2 \rho_{S}}{\lambda_{f}\left[{ }^{238} U\right] L q} \propto \frac{\rho_{S}}{\left[{ }^{238} U\right]}
$$


297 Given this we expect t to be negatively correlated with [U] to some extent (we can 298 imagine plotting $\left.\frac{\rho_{s}}{[U]} v[\mathrm{U}]\right)$. Thus, even on multi-spot data a correlation may exist but 299 it is clearly more important when looking at the single spot data (Fig. S3), and it 300 becomes visible on radial plots.

301 Moreover, when using single U/Ca measurement the dispersion increases, 302 and $\mathrm{p}\left(\chi^{2}\right)$ decreases, compared to the multi-spot results (Fig. 4). Therefore, an 303 inverse correlation between $\mathrm{U} / \mathrm{Ca}$ content and SGA appears along with over304 dispersion. This is illustrated at the scale of a grain in Figure 6a. This radial plot 305 shows SGA for one grain of sample M1. The multi-spot age includes the total number 306 of tracks counted on the larger blue area illustrated on Fig. 1a. As the number of 307 spontaneous tracks appropriately reflects the mean U/Ca measured on the 3 spots, 308 the resultant multi-spot single grain age is in line with the central age of the sample. The "guided" single count is similar to the multi-spot age, but more precise as explained above. Finally spot 1, spot 2 and spot 3 ages use the large area for the spontaneous track count and only one U/Ca measurement. The calculated ages are more precise but more dispersed compare to the central age as the single $\mathrm{U} / \mathrm{Ca}$ 313 measured is not representative of the whole counted area. Several similarly 314 unrepresentative measurements would lead to over-dispersion. Furthermore, the 315 ages are inversely related to the $U$ content. To summarise, both the over-dispersion and inverse correlation are attributable in this example to single spot $\mathrm{U} / \mathrm{Ca}$ measurements not being representative of the mean in the region where the spontaneous tracks were counted for the given grain.

At the scale of the whole M1 sample we also plotted all the possible SGAs 320 depending on which spot is used (i.e. 1 to 4 ages per grain, using the same count 321 and area but the different U/Ca measurements, Fig. 6b). This clearly highlights the 
322 tendency for higher U/Ca to be associated with younger and generally more precise 323 ages (the bottom right part of the radial plot). When considering the ensemble of 324 single spots on figure $6 \mathrm{~b}$ an apparent inverse correlation between $\mathrm{U}$ content and age 325 is obvious. However this is an artefact of the spot position, as the multi-spot and 326 "guided" single spot data (figure 1 b,c) do not show this behaviour. While the 327 zonation is visible on this sample, the same effect would appear on sample on which the zonation would have remained undetected.

Random draw data for Mt Dromedary or FC1 show that, even on relatively unzoned and 'normal' track density samples, misplacing a spot on only few slightly zoned grains can results in an over-dispersion from time to time. On MtDrom especially, about $60 \%$ of our random draws failed the $\chi^{2}$ test despite a low degree of $U$ zoning. As increasing precision of single grain ages increases the possibility of inferring over-dispersion statistically, this is likely due to the relatively high track densities in this sample. As detailed above, over-dispersion of SGA in a sample can also arise from an unrepresentative determination of the $U$ content of the counted area. Thus, with a larger number of tracks the SGA becomes more precise and smaller variations of U/Ca can increase the dispersion.

Therefore, over-dispersion of SGA can be the result of older or younger ages

340 relative to the true age. However, as summarised in Table 2, sample central ages 341 calculated from random draws for single spots are undistinguishable from the central 342 ages determined using the multi-spot data at the $2 \sigma$ level (except for 5 draws out of 3432000 on M1 sample). Even at the $1 \sigma$ level the vast majority of the central ages 344 (almost $100 \%$ of the random draws for most samples, and $>90 \%$ for the others) are 345 undistinguishable from the multi-spot central ages. This is likely the result of 346 compensation between too old grains and too young grains for the single spot data. 
347 This result, based on the experiments presented here, suggests that although the 348 dispersion increases slightly the uncertainty on the single spot central age, it has 349 minimal impact on its accuracy. In case of extreme core rim zonation, the problem 350 could be enhanced but such configuration is probably rare. This is particularly 351 important, because it implies that LA-ICP-MS ages for basement samples that show 352 a high degree of dispersion likely remain accurate, the dispersion potentially coming 353 from undetected zoning and / or spot misplacement during laser ablation. al., 2018, McDannell et al., 2019) could still reflect other controls. As the factors that determine track annealing kinetics are crucial to understand and interpret FT data, it is clearly of primary importance to know if $U$ content is an influential factor or not. In assessing this, we suggest here that when a relationship between $U$ content and SGA is apparent in data collected using one ablation spot per grain, a second LAICP-MS session should be performed to see if this is really linked to $U$ content or may due to initially undetected zoning.

\subsection{Recommendations when dealing with low $\rho_{\mathrm{s}}$ samples}

When the spontaneous track density is too low to visualise possible zonation, three different approaches are possible, (i) counting an area that exactly mimics the ablation spot, (ii) using the mapping approach of Ansberque et al. (2020) and (iii) using the multi-spot approach of Vermeesch et al. (2017). The first solution is the fastest but is not precise as it limits the size of the counting area and consequently reduces the number of countable tracks. The two other approaches are more time 370 consuming, limiting output to roughly two basement samples for a day of ICP-MS 371 analysis. Comparing the samples that were presented in both Ansberque et al. 
372 (2020) and our study (RM 13, HIM622/244 and FCT), it appears that the mapping 373 approach yields more precise SGA data, and so a more precise central age. This is 374 mostly due to the U/Ca measurement protocol and counting statistics. The mapping approach relies on averaging $\mathrm{U} / \mathrm{Ca}$ for all pixels of the grain map. Given a pixel is 376 about $3.5 \mu \mathrm{m}$ wide, one ends up with a few hundred pixels for a grain and thus a few 377 hundred U/Ca ratios. With the multi-spot approach, we typically use 3 to 4 spots per grain. It is obvious that the standard error of the mean U/Ca concentration will be larger with four counts than with a few hundred and so leads to a less precise age estimate. However, the mapping approach necessitates equipment and materials that are not currently available in all LA-ICP-MS laboratories. Additionally, once one has decided to use the mapping approach, it has to be done for the whole sample and this choice implies half a day of ICP-MS time. In contrast the multi-spot approach is more practical and flexible for basement samples as one could decide to do only one spot during a first session. If the single grain dispersion is low then there is no obvious need to perform more analysis. Alternatively, if the dispersion is high, one should do more spots, at least on the grains that are responsible for the overdispersion, to assess if the dispersion reflects a zoning issue or could be a sign of differential annealing behaviour. For detrital samples, the preferred procedure is harder to define as we may anticipate multiple age populations and different 391 annealing effects, typically requiring analysis of a large number of grains (c. 120 grains per sample) to characterise adequately the distribution of SGA. Using the multi-spot approach on for each grain would be time consuming but in detrital samples, one cannot generally rely on the SGA dispersion to indicate analytical issues. In such cases it is possible to try and initially characterise different 396 populations using other data acquired simultaneously, such as U-Pb ages or trace 
element concentrations (e.g. O'Sullivan et al., 2020, Westerweel et al., 2020). Then, at least in principle, different populations or components can be isolated and the analyst can decide if more spots are needed on some grains.

\section{5- Conclusion}

In this study we assessed the multi-spot approach proposed by Vermeesch (2017) in terms of its ability to decrease SGA dispersion in low $\rho_{s}$ and / or zoned samples. It also increases the precision on the central age by allowing the counting larger areas. Our results show that this method is efficient and should be used when SGA over-dispersion is apparent for a basement sample. Moreover, we show that an inverse correlation between SGA and $\mathrm{U}$ content coupled to over dispersion can be induced due to zoning and single spot $U$ contents being unrepresentative of the whole grain. This means that $U$ zoning could give a potentially false impression that high/low $U$ content leads to faster/slower annealing. Therefore, it is important to assess if multi-spot datasets continue to give such relationships in slowly cooled basement samples to better understand and better interpret FT data.

\section{$\underline{\text { 6- Acknowledgements }}$}

NC thanks the following people for sharing their samples: Marc Jolivet for SG9, SG10 and SG19, Claire Ansberque for RM13 and HIM 622/244, Simon Nachtergaele for FC1, Stéphanie Brichau for M1 and Raymond Donelick for Mt Drom and FCT. We thank S. Glorie for his comments that improved the manuscript. We also thank P. Vermeesch for his helpful review and especially for his comments (including eq. 2 and the reference to Pearson 1986) about the expected U - SGA correlation. 


\section{$423 \quad$ 7-References}

424 Ansberque, C., Chew, D.M., Drost, K. 2021, Apatite fission-track dating by LA-Q-ICP$425 \quad$ MS mapping. Chemical Geology, 560, 119977.

426 Boehnke, P., Harrison, M.T., 2014. A meta-analysis of geochronologically relevant half-lives: what's the best decay constant? International Geology Review, 56, 905-914.

429

430

Brichau, S., Ring, U., Carter, A., Bolhar, R., Monié, P., Stockli, D., Brunel, M., 2008. Timing, slip rate, displacement and cooling history of the Mykonos detachment footwall, Cyclades, Greece, and implications for the opening of the Agean Sea basin. Journal of the Geological Society 165, 263-277.

Chew, D.M., Donelick, R.A., 2012. Combined apatite fission track and U-Pb dating by LA-ICP-MS and its application in apatite provenance analysis. Mineralogical Association of Canada Short Course 42, 219-247.

Chew, D.M., Babechuk, M.G., Cogné, N., Mark, C., O'Sullivan, G.J., Henrichs, I.A., Doepke, D., McKenna, C.A., 2016. (LA,Q)-ICPMS trace-element analyses of Durango and McClure Mountain apatite and implications for making natural LAICPMS mineral standards. Chemical Geology, 435, 35-48.

Cogné, N., Chew, D.M., Stuart, F.M., 2014. The thermal history of the western Irish onshore. Journal of the Geological Society, 171, 779-792.

Cogné, N., Doepke, D., Chew, D.M., Stuart, F.M., Mark, C., 2016. Measuring plumerelated exhumation of the British Isles in Early Cenozoic times. Earth and Planetary Science Letters 456, 1-15. 
445 Cogné N., Chew., D.M., Donelick, R.A., Ansberque, C., 2020. LA-ICP-MS apatite fission track dating: a practical zeta-based approach. Chemical Geology 531, 119302

De Grave, J., Glorie, S., Ryabinin, A., Zhimulev, F., Buslov, M.M., Izmer, A., Elburg, M., Vanhaecke, F., Van den haute,P., 2012. Late Palaeozoic and MesoCenozoic tectonic evolution of the southern Kyrgyz Tien Shan: Constraints from multi-method thermochronology in the Trans-Alai, Turkestan-Alai segment and the southeastern Ferghana Basin. Journal of Asian Earth Sciences, 44, 149-168.

Donelick, R.A., O'Sullivan, P.B., Ketcham, R.A., 2005. Apatite Fission-Track Analysis. Reviews in Mineralogy and Geochemistry 58, 49-94.

Fernie, N., Glorie, S., Jessel, M.W., Collins, Collins, A.S., 2018. Thermochronological insights into reactivation of a continental shear zone in response to Equatorial Atlantic rifting (northern Ghana). Scientific Reports 8, 16619.

Gleadow, A., Harrison, M., Kohn, B., Lugo-Zazueta, R., Phillips, D., 2015. The Fish Canyon Tuff: a new look at an old low-temperature thermochronology standard. Earth and Planetary Science Letters 424, 95-108.

Hasebe, N., Barbarand, J., Jarvis, K., Carter, A., Hurford, A.J., 2004. Apatite fissiontrack chronometry using laser ablation ICP-MS. Chemical Geology 207, 135-145.

Hendriks B. and Redfield T. (2005) Apatite fission track and (U- Th)/He data from Fennoscandia: an example of underestimation of fission track annealing in apatite. Earth and Planetary Science Letters 236, 443-458.

Henrichs, I.A., O’Sullivan, G.J., Chew, D.M., Mark, C., Babechuk, M.G., McKenna, C., Emo R., 2018. The trace element and U-Pb systematics of metamorphic apatite. Chemical Geology, 483, 218-238. 
469 Hurford, A.J., 1990. Standardization of fission track dating calibration: 470 Recommendation by the Fission Track Working Group of the I.U.G.S. 471 Subcommission on Geochronology. Chemical Geology 80, 171-178.

472 Hurford, A.J., Green, P.F., 1983. The zeta age calibration of fission-track dating. $473 \quad$ Chemical Geology 41, 285-317.

474 Iwano, H., Danhara, T., Yuguchi, T., Hirata, T., \& Ogasawara, M., 2019. Duluth complex apatites: Age reference material for LA-ICP-MS- based fission-track dating. Terra Nova, 31, 247-256.

Jolivet, M., Roger, F., Xu, Z.Q., Paquette, J-L, Cao, H., 2015. Mesozoic-Cenozoic evolution of the Danba dome (Songpan Garzê, East Tibet) as inferred from LAICPMS U-Pb and fission-track data. Journal of Asian Earth Sciences 102, 180 204.

Ketcham, R.A., van der Beek, P., Barbarand, J., Bernet, M., Gautheron, C., 2018. Reproducibility of thermal history reconstruction from apatite fission-track and (UTh)/He data. Geochemistry, Geophysics, Geosystems, 19, 2411-2436.

Kohn B. P., Lorencak M., Gleadow A. J., Kohlmann F., Raza A., Osadetz K. G., 485 Sorjonen-Ward P., 2009. A reappraisal of low-temperature thermochronology of the eastern Fennoscandia Shield and radiation-enhanced apatite fission-track annealing. In: Lisker, F., Ventura, B., Glasmacher, U.A. (Eds.).

McDannell, K.T., Issler, D.R., O'Sullivan, P.B., 2019, Geochimica et Cosmochimica Thermochronological methods: from paleotemperature constraints to landscape evolution models. Geological Society of London Special Publication 324, 193216. Acta, Radiation-enhanced fission track annealing revisited and consequences for apatite thermochronometry, 252, 213-239. 
McDougall, I., Wellman, P., 2011. Calibration of GA1550 biotite standard for K/Ar and ${ }^{40} \mathrm{Ar} /{ }^{39} \mathrm{Ar}$ dating. Chemical Geology, 280, 19-25.

O'Sullivan, G.O., Chew, D., Kenny, G., Henrichs, I., Mulligan, D., 2020. The trace element composition of apatite and its application to detrital provenance studies. Earth-Science Reviews, 201, 103044.

Paton, C., Hellstrom, J., Paul, B., Woodhead, J., Hergt, J., 2011. Iolite: Freeware for the visualisation and processing of mass spectrometric data. Journal of Analytical Atomic Spectrometry 26, 2508-2518.

Pearson, K. 1896. Mathematical contributions to the theory of evolution.-On a form of spurious correlation which may arise when indices are used in the measurement of organs. Proceedings of the Royal Society of London, 60, 489-498.

Price, P., Walker, R., 1962. Observation of Fossil Particle Tracks in Natural Micas. Nature 196, 732-734.

Soares, C., Guedes, S., Hadler, J., Mertz-Kraus, R., Zack, T., lunes, P., 2014. Novel calibration for LA-ICP-MS-based fission-track thermochronology. Physics and Chemistry of Minerals 41, 65-73.

Treloar, P.J., Rex, D.C., Guise, P.G., Wheeler, J., Hurford, A.J., Carter, A., 2000. Geochronological constraints on the evolution of the Nanga Parbat syntaxis, Pakistan Himalaya. In: Khan, M.A., Treloar, P.J., Searle, M.P., Jan, M.Q. (Eds). Tectonics of the Nanga Parbat Syntaxis and the Western Himalaya. Geological Society of London Special Publication 170, 137-162.

Vermeesch, P., 2017, Statistics for LA-ICP-MS based fission track dating. Chemical Geology, 456, 19-27.

Vermeesch, P., 2018. IsoplotR: A free and open toolbox for geochronology. Geosciences Frontiers, 5, 1479-1493. 

one random draw. The data are over-dispersed and SGA seems related to the U/Ca

Vermeesch, P., 2019. Statistics for fission-track thermochronology, in: Fission-track thermochronology and its application to geology, M. Malusà and P. Fitzgerald Eds., Springer, Berlin. 393pp.

Westerweel, J., Licht, A., Cogné, N., Roperch, P., Dupont-Nivet, G., Kay Thi, M., Swe, H. H., Huang, H., Win, Z., Aung, D.W., 2020. Burma Terrane collision and northward indentation in the Eastern Himalayas recorded in the Eocene-Miocene Chindwin Basin (Myanmar). Tectonics, 39, e2020TC006413.

Woodhead, J., Hellstrom, J., Hergt, J., Greig, A. and Maas, R., 2007. Isotopic and elemental imaging of geological materials by laser ablation Inductively Coupled Plasma mass spectrometry. Journal of Geostandards and Geoanalytical Research 31, 331-343.

\section{Figure caption}

Table 1: Samples used in this study.

Table 2: Results for fission track analysis and random draws. Detailed grain data are provided in supplementary material.

Figure 1: Example of grain area determination and data for M1 sample (a) Example of how we used two different spontaneous track counting areas, the emplacement of the three ablation spots and the counted tracks. (b) Radial plots for the multi-spot data. (c) Radial plots of the "guided" single spot data (counted area close in size and shape to the ablation spot and from a region relatively unzoned). (d) Radial plots of content. See text for further discussion. 
546 Figure 2: Plot of the central ages calculated in this study versus literature central 547 ages for all samples. Note the logarithmic scale for both axis and the break on the y548 axis. The dashed line is the $1: 1$ line

Figure 3: Radial plots for all samples using multi-spot data. All samples yield ages in 551 agreement with the published values and show a low degree of dispersion. $\mathrm{CA}=$ 552 Central age

554 Figure 4: (a) The proportion of random draws that pass the $\chi 2$ test $(p(\chi 2)>0.05)$ 555 versus the U/Ca variation in the sample, showing a negative correlation.. (b) Mean 556 dispersion of the 2000 random draws versus the U/Ca variation in the sample, 557 showing a positive correlation..

559 Figure 5: An example of the random sampling to simulate single spot data for the 560 different samples. For all samples the SGA dispersion increases compared to the 561 multi-spot data (Fig. 3). In some samples the SGA seem correlated to U/Ca content 562 (color-coded for each grain) - younger and often more precise ages with higher U/Ca. 563 However, all central ages are undistinguishable from those estimated with the multi564 spot data. $\mathrm{CA}=$ Central age

566 Figure 6: (a) Radial plot of a single grain age from M1 grain 30 data calculated using 567 multi-spot, "guided" single count (tracks counted in the white area in Fig. 1a), and 568 spot 1 , spot 2, spot 3 , that use tracks counted in the blue area in Fig. 1a and the 
569 measured U/Ca ratio from spot 1, 2 or 3 respectively. Spot 1 samples more or less

570 the average $\mathrm{U} / \mathrm{Ca}$ ratio. We see that when the ablation spot hits a higher than 571 average $U$ area, the age is younger (spot 3 ) while when it hits a lower $U$ area the age 572 is older (spot 2). (b) Radial plots of all the possible SGA, implying an apparent 573 inverse relation between U/Ca content and SGA. See text for further discussion.

574

575 


\begin{tabular}{|c|c|c|c|c|}
\hline $\begin{array}{l}\text { Sample Name and } \\
\text { Location }\end{array}$ & lithology & Reported age & Characteristics & Reference \\
\hline Fish Canyon tuff (USA) & Tuff & $28.1 \pm 0.1$ & Age standard & Boenhnke and Harrison, 2014 \\
\hline $\begin{array}{l}\text { Mt Dromedary (NSW, } \\
\text { Australia) }\end{array}$ & Granite & $98.5 \pm 0.5$ & Age standard & McDougall and Wellman, 2011 \\
\hline $\begin{array}{c}\text { FC1 (Duluth Complex, } \\
\text { USA) }\end{array}$ & $\begin{array}{l}\text { Anorthositic } \\
\text { serie }\end{array}$ & $861 \pm 29^{\circ} *$ & $\begin{array}{c}\text { proposed reference } \\
\text { material; low exhumation } \\
\text { rate }\end{array}$ & Iwano et al., 2019 \\
\hline M1 (Mykonos, Greece) & Monzogranite & $12.5 \pm 2.2^{*}$ & $\begin{array}{c}\text { High track density; visible } \\
\text { zonation; high } \\
\text { exhumation rate }\end{array}$ & Brichau et al., 2008 \\
\hline RM13 (Paros, Greece) & Paragneiss & $9.9 \pm 0.6^{\circ}$ & $\begin{array}{c}\text { low track density; known } \\
\text { zonation; high } \\
\text { exhumation rate } \\
\end{array}$ & $\begin{array}{l}\text { Henrichs et al., 2018; } \\
\text { Ansberque et al., } 2020\end{array}$ \\
\hline Pb1 (Wales) & Granite & $220.8 \pm 52.0^{\circ}$ & $\begin{array}{l}\text { low track density; } \\
\text { possible zonation; low } \\
\text { exhumation rate }\end{array}$ & Cogné et al., 2016 \\
\hline $\begin{array}{c}\text { HIM 622/244 ( Nanga } \\
\text { Parbat Massif, Pakistan) }\end{array}$ & Gneiss & $\begin{array}{c}0.03 \pm 0.04^{*} \\
0.8 \pm 0.3^{\circ}\end{array}$ & $\begin{array}{l}\text { very low track density; } \\
\text { possible zonation, high } \\
\text { exhumation rate }\end{array}$ & $\begin{array}{c}\text { Treloar et al., 2000; } \\
\text { Ansberque et al., } 2020\end{array}$ \\
\hline $\begin{array}{l}\text { SG9 (Danba Dome, } \\
\text { Eastern Tibet) }\end{array}$ & Gneiss & $5.7 \pm 0.7^{*}$ & $\begin{array}{c}\text { low track density; } \\
\text { possible zonation, high } \\
\text { exhumation rate } \\
\end{array}$ & Jolivet et al., 2015 \\
\hline $\begin{array}{l}\text { SG10 (Danba Dome, } \\
\text { Eastern Tibet) }\end{array}$ & $\begin{array}{l}\text { Leucocratic } \\
\text { dyke }\end{array}$ & $4.5 \pm 0.6^{*}$ & $\begin{array}{c}\text { low track density; } \\
\text { possible zonation, high } \\
\text { exhumation rate } \\
\end{array}$ & Jolivet et al., 2015 \\
\hline $\begin{array}{l}\text { SG19 (Danba Dome, } \\
\text { Eastern Tibet) }\end{array}$ & Granite & $4.7 \pm 0.7^{*}$ & $\begin{array}{l}\text { low track density; } \\
\text { possible zonation, high } \\
\text { exhumation rate }\end{array}$ & Jolivet et al., 2015 \\
\hline
\end{tabular}

\footnotetext{
- Reference Age determined with LA-ICP-MS

* Reference Age determined withEDM
} 


\begin{tabular}{|c|c|c|c|c|c|c|c|c|c|c|c|c|c|c|}
\hline & nb grains & Ns & Area $(\mathrm{cm} 2)$ & $\rho s$ (track/cm2) & $\mathrm{U} / \mathrm{Ca}$ & $\mathrm{p}\left(\chi^{2}\right)$ & Dispersion (\%) & $\begin{array}{c}\text { central age } \pm 2 \sigma \\
(\mathrm{Ma})\end{array}$ & $\begin{array}{c}\text { pooled age } \pm 2 \sigma \\
(\mathrm{Ma})\end{array}$ & reference age $\pm 2 \sigma(\mathrm{Ma})$ & $\begin{array}{c}\text { Uranium } \\
\text { variation (a) }\end{array}$ & $\begin{array}{c}\text { Random } \\
\text { Ages (\%) (b) } \\
\end{array}$ & $\begin{array}{c}\text { Random } \\
\mathrm{p}\left(\chi^{2}\right)(\%)(\mathrm{c})\end{array}$ & $\begin{array}{c}\text { Random } \\
\text { dispersion (d) }\end{array}$ \\
\hline M1 (Single spot) & 30 & 754 & $6.33 \mathrm{E}-04$ & $1.19 \mathrm{E}+06$ & $1.03 \mathrm{E}-01$ & 0.06 & 13.2 & $10.3 \pm 0.9$ & $10.0 \pm 0.8$ & $12.5 \pm 2.2^{*}$ & - & & & \\
\hline M1 (Multi spots) & 30 & 1642 & $1.63 \mathrm{E}-03$ & $1.00 \mathrm{E}+06$ & $7.25 \mathrm{E}-02$ & 1 & 0 & $10.0 \pm 1.5$ & $9.6 \pm 1.8$ & $12.5 \pm 2.2^{*}$ & $0.37 \pm 0.05$ & \begin{tabular}{|l|}
$99.9 / 92.9$ \\
\end{tabular} & 0 & $0.53[0.36-0.66]$ \\
\hline RM13 & 40 & 244 & $2.29 \mathrm{E}-03$ & $1.06 \mathrm{E}+05$ & $6.94 \mathrm{E}-03$ & 0.87 & 0 & $11.2 \pm 1.7$ & $10.3 \pm 1.6$ & $9.9 \pm 0.6^{\circ}$ & $0.22 \pm 0.02$ & $100 / 99.9$ & 37.1 & $0.26[0.00-0.44]$ \\
\hline SG9 & 30 & 145 & $1.40 \mathrm{E}-03$ & $1.03 \mathrm{E}+05$ & $1.50 \mathrm{E}-02$ & 0.97 & 0 & $5.0 \pm 1.1$ & $4.7 \pm 1.0$ & $5.7 \pm 0.7^{*}$ & $0.31 \pm 0.06$ & $100 / 98.5$ & 19.9 & $0.44[0.00-0.74]$ \\
\hline SG10 & 29 & 70 & $1.79 \mathrm{E}-03$ & $3.91 \mathrm{E}+04$ & $6.45 \mathrm{E}-03$ & 0.93 & 0 & $5.2 \pm 1.3$ & $4.4 \pm 1.1$ & $4.5 \pm 0.6^{*}$ & $0.14 \pm 0.02$ & $100 / 100$ & 100 & $0.00[0.00-0.12]$ \\
\hline SG19 & 30 & 62 & $1.82 \mathrm{E}-03$ & $3.40 \mathrm{E}+04$ & $4.75 \mathrm{E}-03$ & 1 & 0 & $5.5 \pm 1.4$ & $4.9 \pm 1.3$ & $4.7 \pm 0.7^{*}$ & $0.12 \pm 0.02$ & $100 / 100$ & 100 & $0.00[0.00-0.00]$ \\
\hline $\mathrm{Pb} 1$ & 28 & 228 & $9.95 \mathrm{E}-04$ & $2.29 \mathrm{E}+05$ & $7.33 \mathrm{E}-04$ & 0.94 & 0 & $214.8 \pm 34.0$ & $203.3 \pm 34.6$ & $220.8 \pm 52.0^{\circ}$ & $0.19 \pm 0.06$ & \begin{tabular}{|l|}
$100 / 99.6$ \\
\end{tabular} & 74.8 & $0.19[0.00-0.52]$ \\
\hline FC1 & 20 & 1862 & $7.60 \mathrm{E}-04$ & $2.45 \mathrm{E}+06$ & $1.83 \mathrm{E}-03$ & 0.92 & 0 & $882.4 \pm 44.4$ & $879.7 \pm 46.6$ & $861 \pm 29^{\circ *}$ & $0.04 \pm 0.01$ & $100 / 99.8$ & 91.2 & $0.04[0.00-0.11]$ \\
\hline HIM622/244 & 50 & 30 & $8.21 \mathrm{E}-03$ & $3.65 \mathrm{E}+03$ & $5.56 \mathrm{E}-03$ & 0.2 & 37.5 & $1.2 \pm 0.5$ & $0.45 \pm 0.21$ & $0.03 \pm 0.04^{*} ; 0.8 \pm 0.3^{\circ}$ & $0.64 \pm 0.04$ & $100 / 100$ & 0 & $0.62[0.55-0.74]$ \\
\hline Fish Canyon Tuff & 28 & 236 & $1.23 \mathrm{E}-03$ & $1.92 \mathrm{E}+05$ & $4.81 \mathrm{E}-03$ & 0.84 & 0 & $29.0 \pm 4.0$ & $27.7 \pm 3.8$ & $28.1 \pm 0.1$ & $0.09 \pm 0.01$ & $100 / 100$ & 100 & $0.01[0.00-0.14]$ \\
\hline MtDromedary & 20 & 945 & $7.38 \mathrm{E}-04$ & $1.28 \mathrm{E}+06$ & $9.13 \mathrm{E}-03$ & 0.63 & 0 & $96.5 \pm 7.0$ & $95.8 \pm 7.1$ & $98.5 \pm 0.5$ & $0.06 \pm 0.01$ & \begin{tabular}{|l|}
$100 / 99.5$ \\
\end{tabular} & 40.9 & $0.11[0.00-0.19]$ \\
\hline
\end{tabular}

- Reference Age determined with LA-ICP-MS

* Reference Age determined withEDM

(a) Defined as the average \pm standard deviation of the relative standard deviation of $\mathrm{U} / \mathrm{Ca}$ ratio of each grain

of random draw that yielded the same central age than multiple spots within $2 \sigma /$ within $1 \sigma$

(c) Percentage of random draw that have $\mathrm{p}\left(\chi_{2}\right)>0.05$

(d) Average and $95 \%$ asymetric interval of dispersion of single grain age of random draw 


\section{Figure 1}
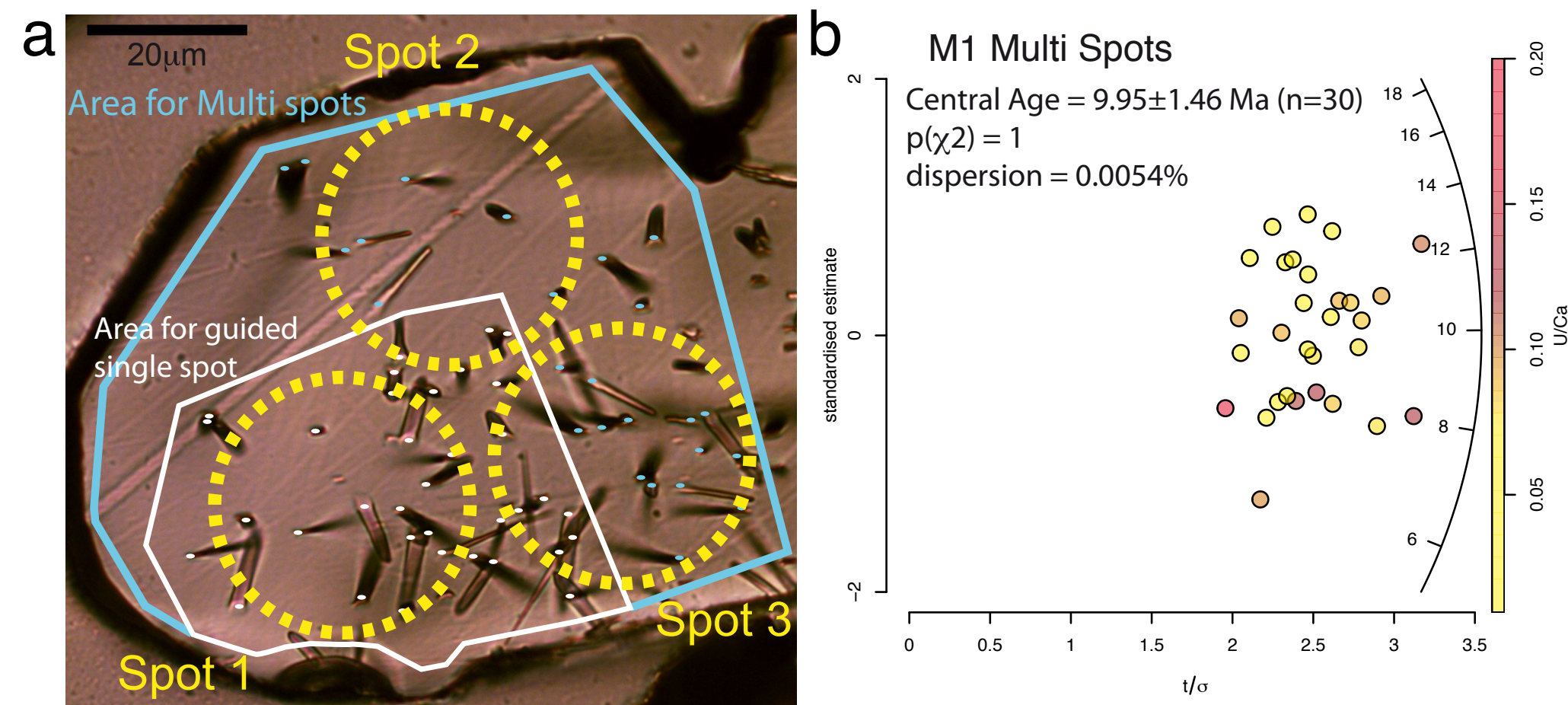

C

M1 "guided" single spot

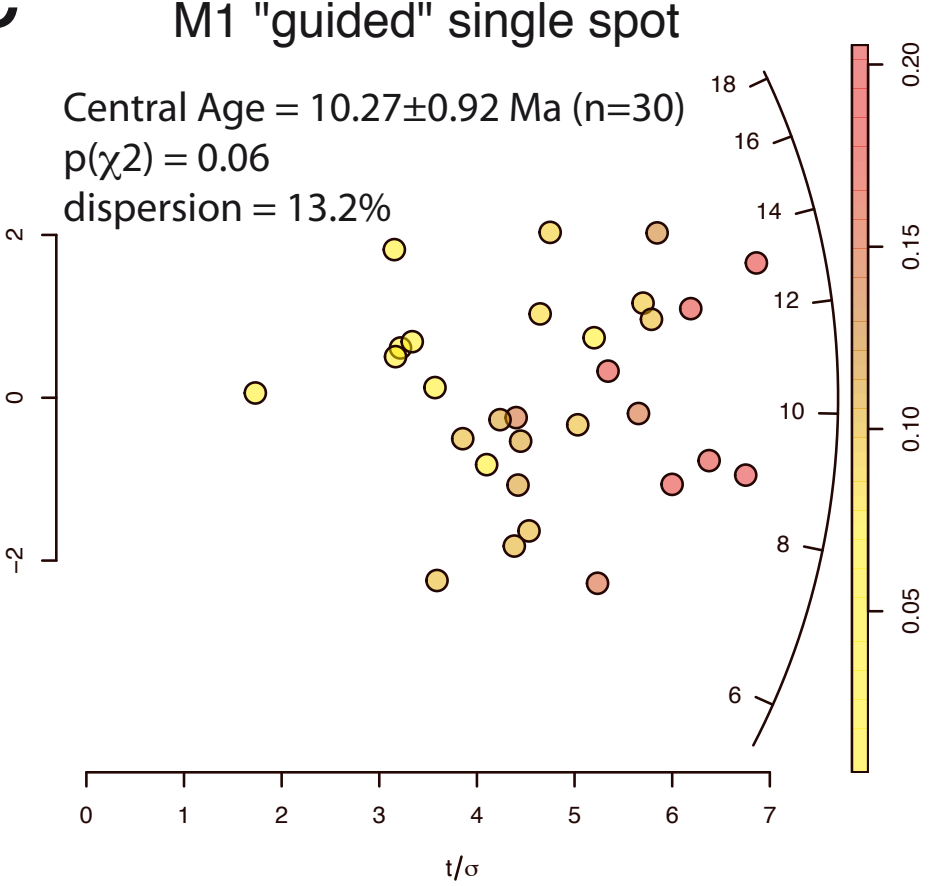

d

M1 Random Single Spot

Central Age $=10.54 \pm 1.92 \mathrm{Ma}(\mathrm{n}=30)$ $\mathrm{p}(\chi 2)=0$

dispersion $=46.7 \%$

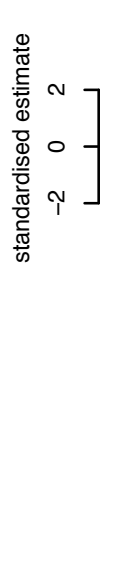

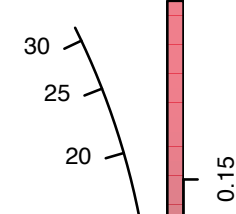

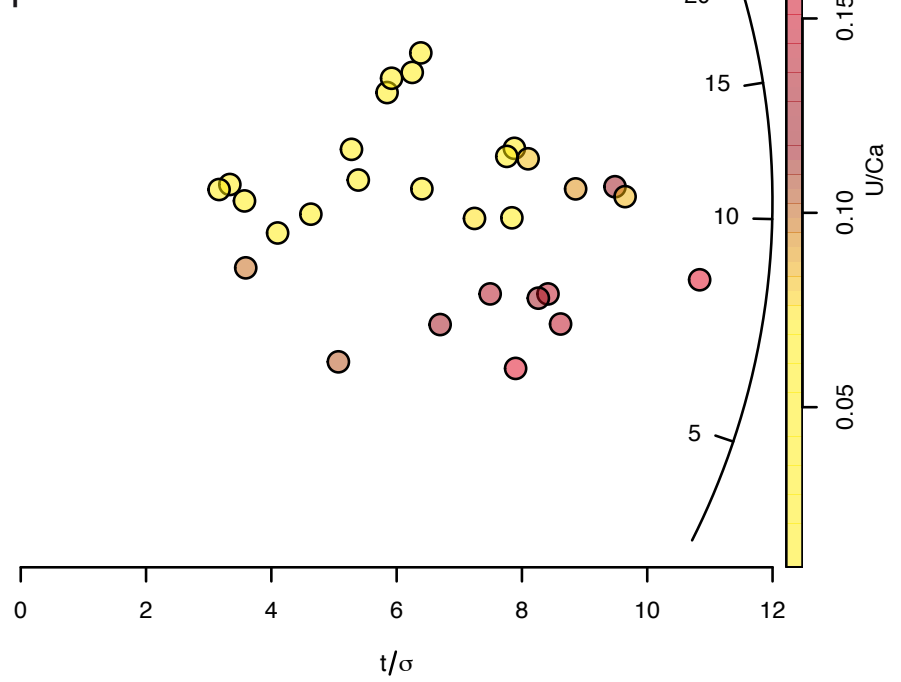




\section{Figure 2}

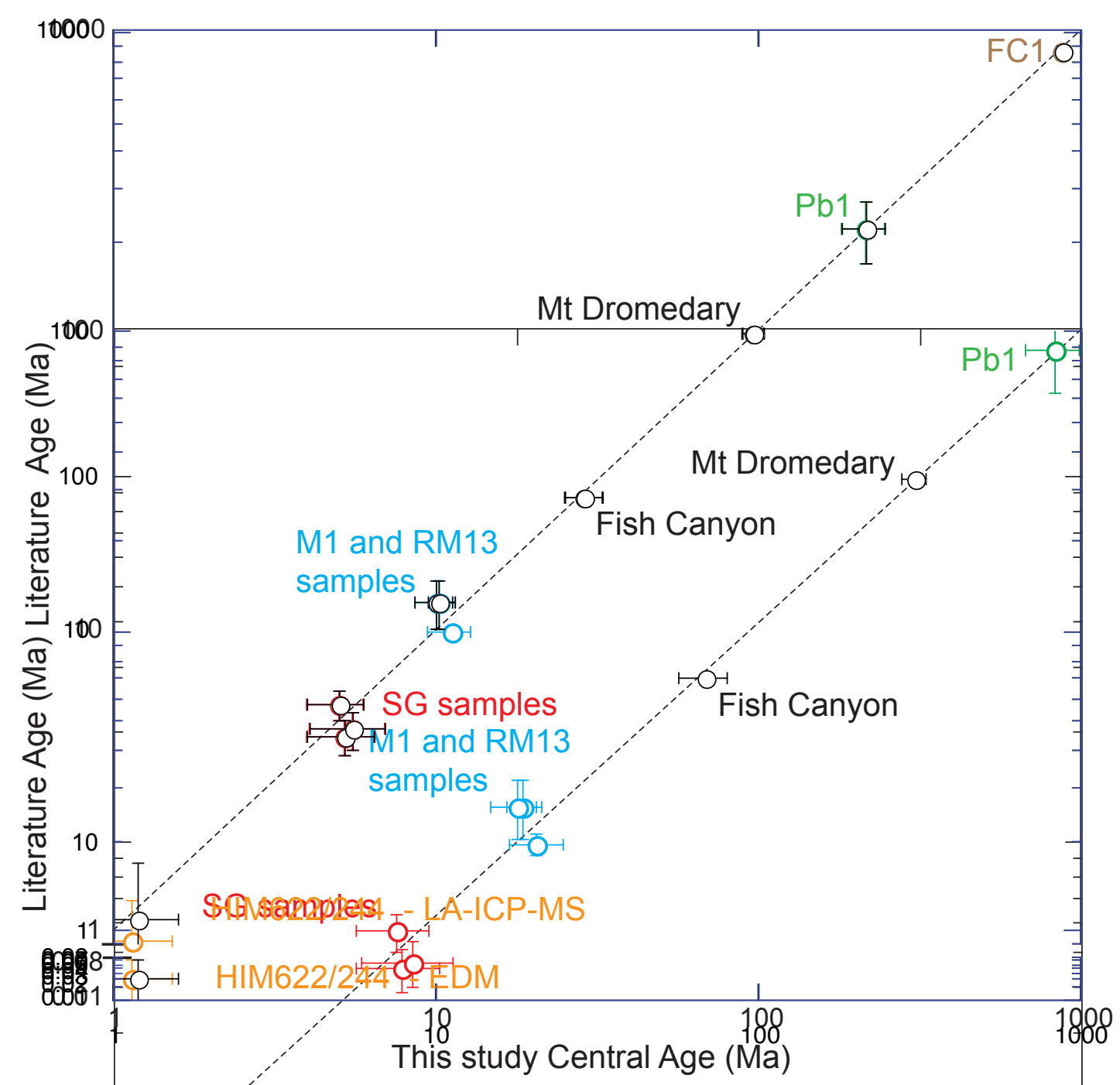



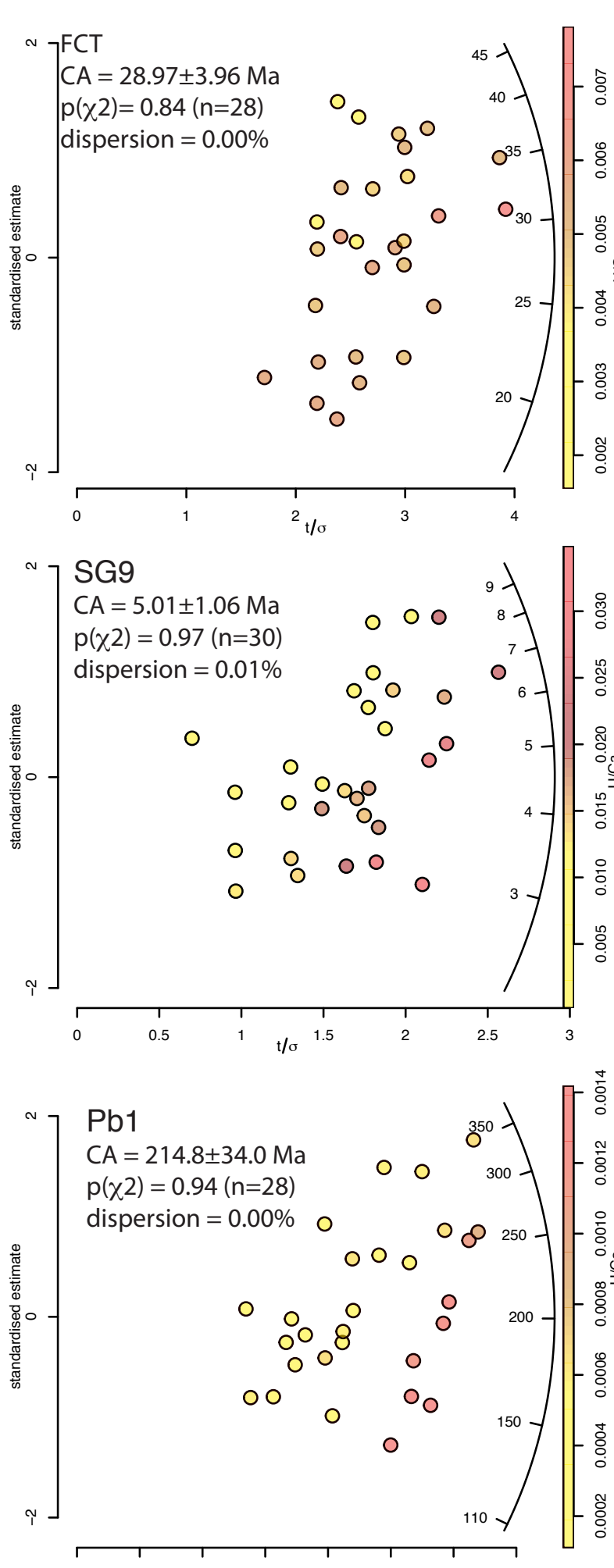
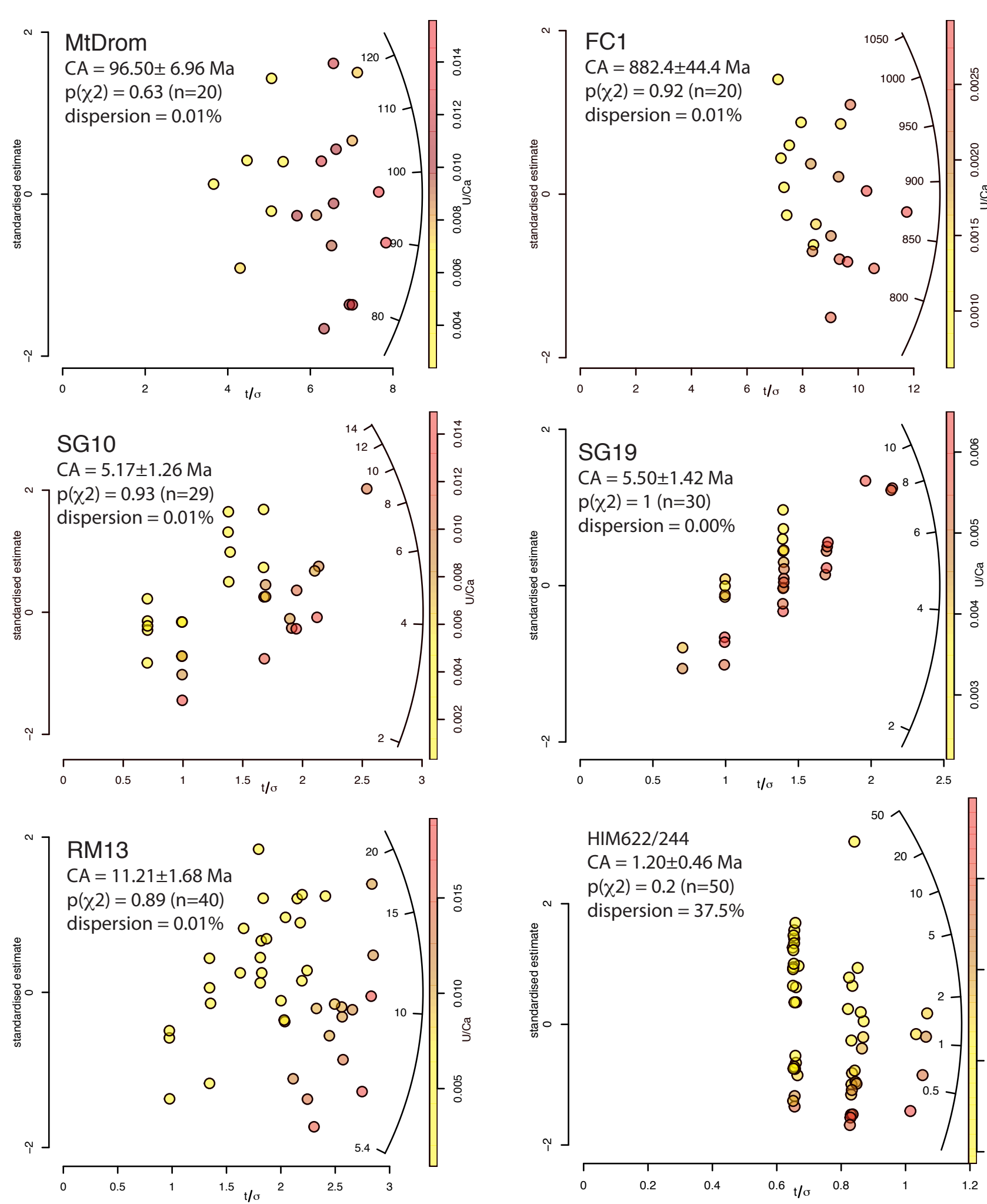
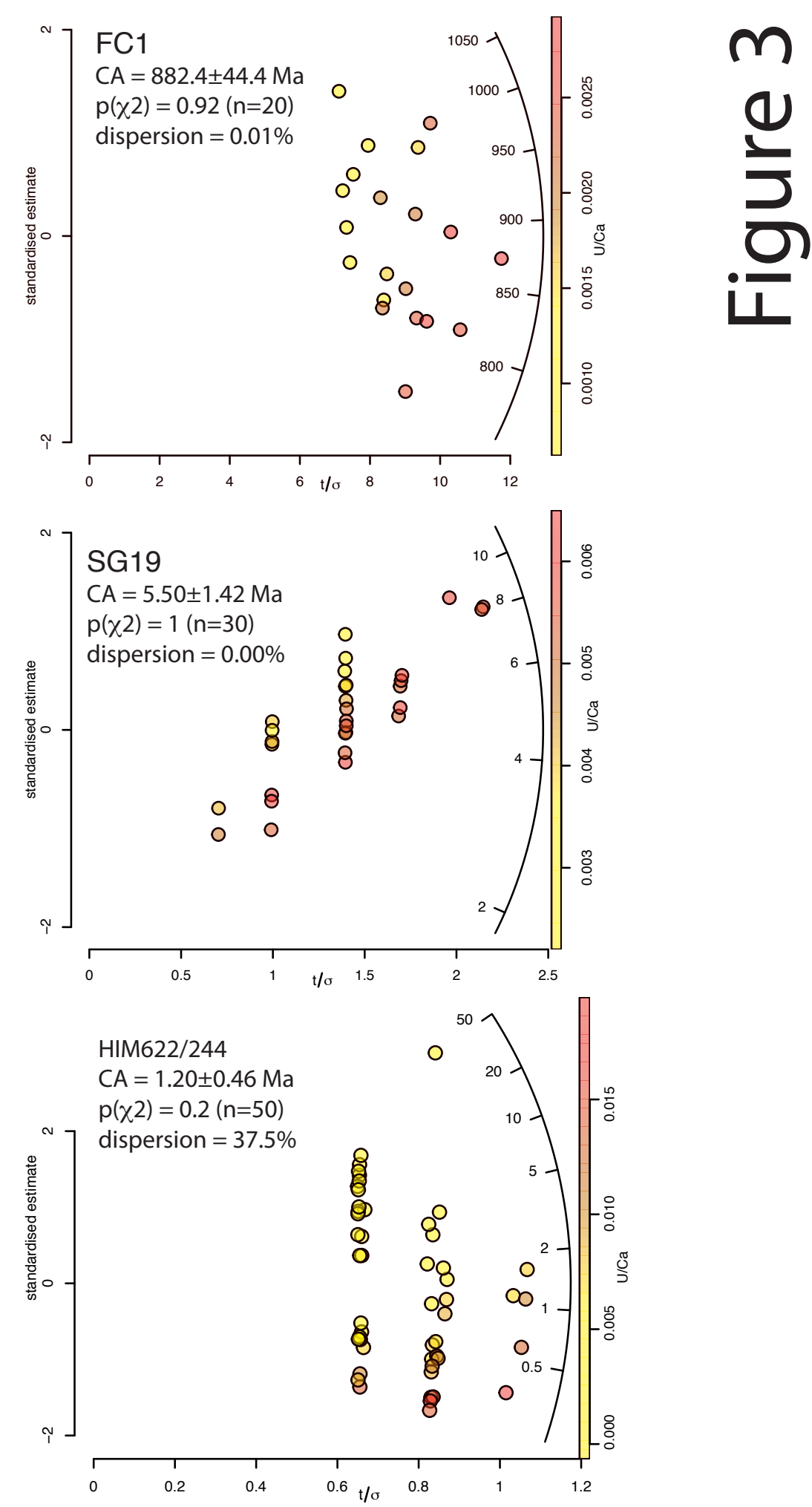
FCT

$C A=28.33 \pm 2.82 \mathrm{Ma}$

$\mathrm{p}(\chi 2)=0.32(\mathrm{n}=28)$

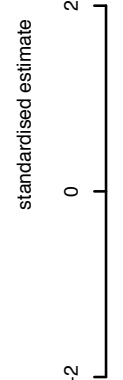

dispersion $=7.8 \%$

\section{(}

SG9

$\mathrm{CA}=5.34 \pm 1.44 \mathrm{Ma}$

$\mathrm{p}(\chi 2)=0.0(\mathrm{n}=30)$ dispersion $=51.7 \% \circ{ }^{\circ}$

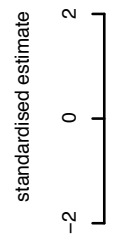

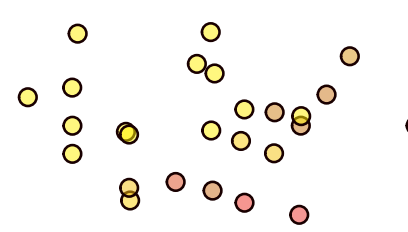

\section{$\mathrm{Pb} 1$}

$\mathrm{CA}=208.7 \pm 33.2 \mathrm{Ma}$ $\mathrm{p}(\chi 2)=0.084(\mathrm{n}=28)$ dispersion $=19.9 \%$

o $\begin{array}{ccccccc}0 & 0 & 0 & 0 & 0 & \\ 0 & 0 & 8 & 8 & 0 & & 300 \\ 0 & 0 & 0 & & \\ 0 & & & & 0\end{array}$
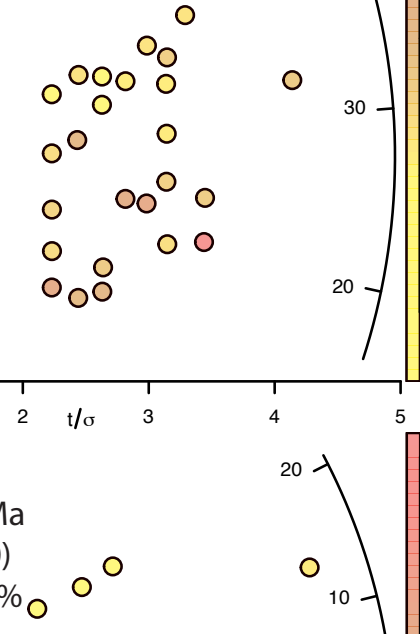

1.4

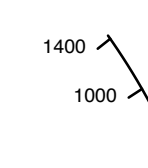

MtDrom

$\mathrm{p}(\chi 2)=0.016(\mathrm{n}=20) \mathrm{O}$

dispersion $=13.1 \%$

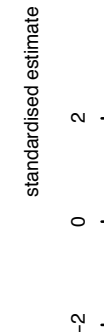

$110-1$

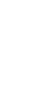

$$
-1
$$

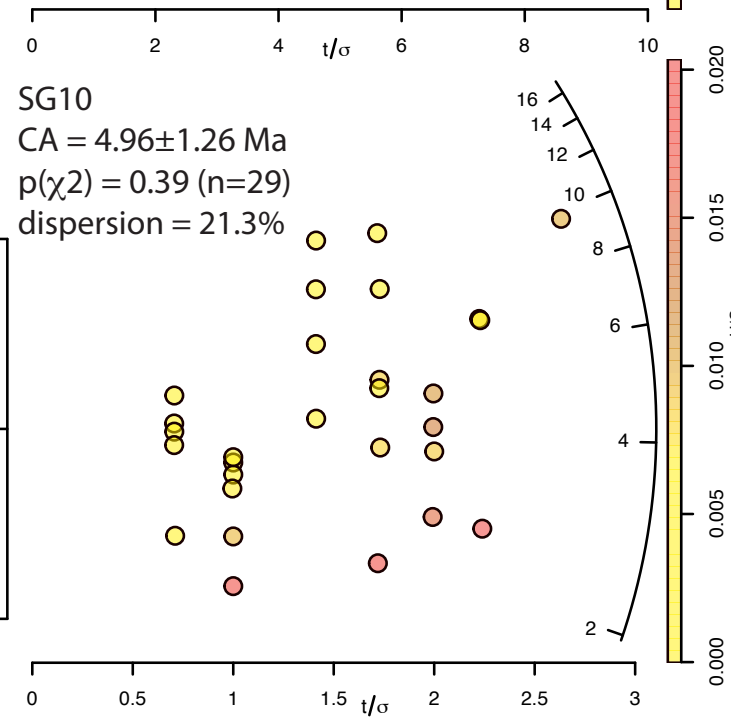

○ $\infty$

o
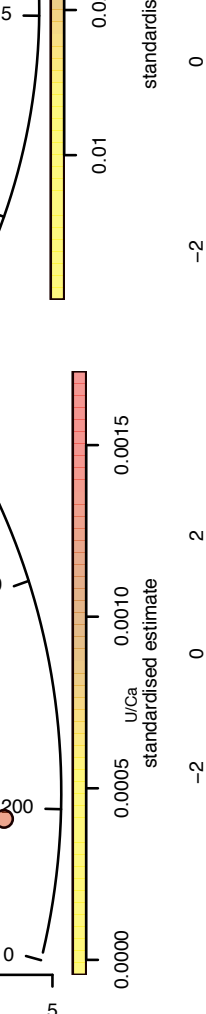

\section{RM13}

$\mathrm{CA}=12.05 \pm 2.44 \mathrm{Ma}$

$\mathrm{p}(\chi 2)=0.00(\mathrm{n}=40)$
$\sim{ }^{\text {dispersion }}=45.9 \%$

]$^{\text {dispersion }}=45.9 \%$ ○
FC1

$\mathrm{CA}=865.3 \pm 62.0 \mathrm{Ma}$

$p(\chi 2)=0.002(n=20)$

dispersion $=11.4 \%$

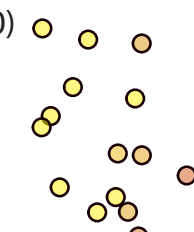

० 08

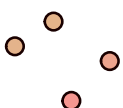

0 


\section{Figure 6}

a

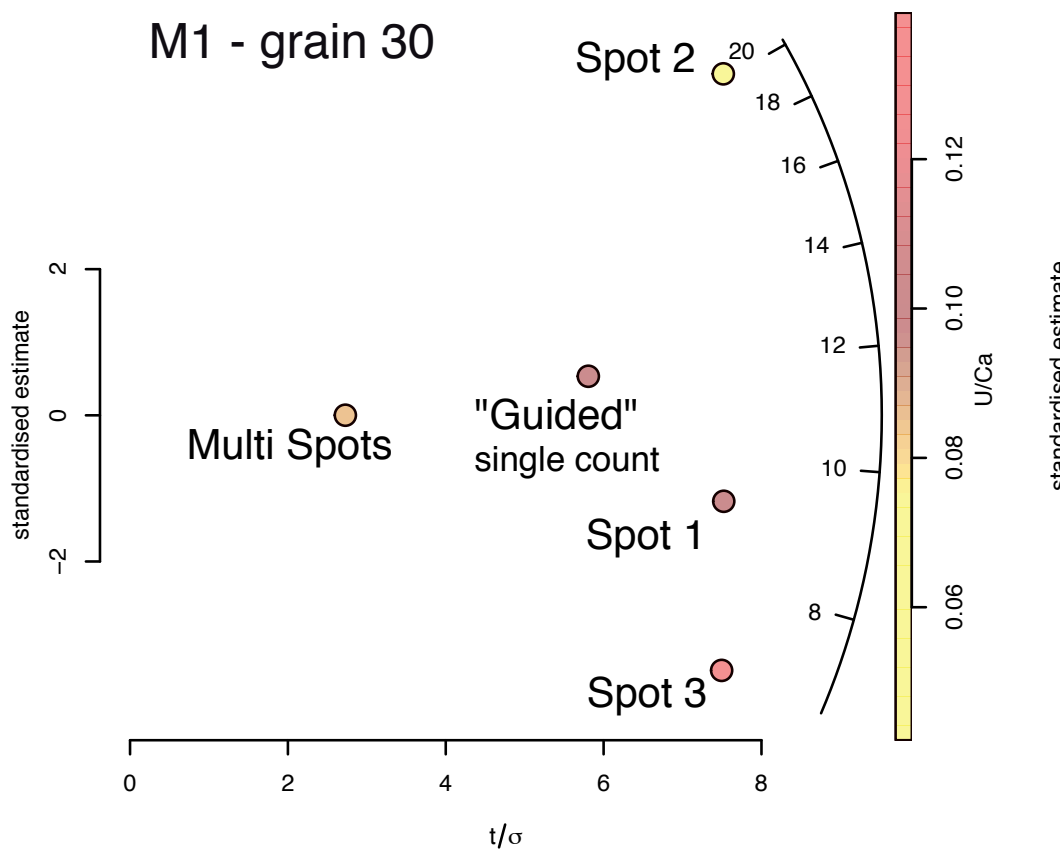

b M1 - All age data

Central Age $=9.98 \pm 1.18 \mathrm{Ma}(\mathrm{n}=95)$ $\mathrm{p}\left(\chi_{2}\right)=0$

dispersion $=55.3 \%$

0

8

$\left.\begin{array}{l}\sim \\ 0 \\ \uparrow\end{array}\right]$

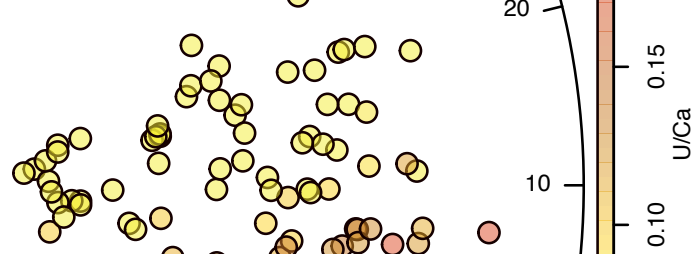

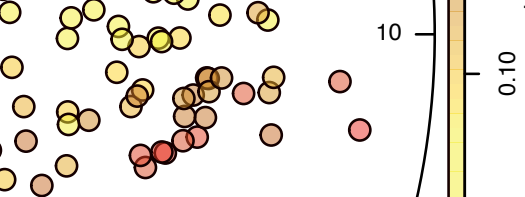

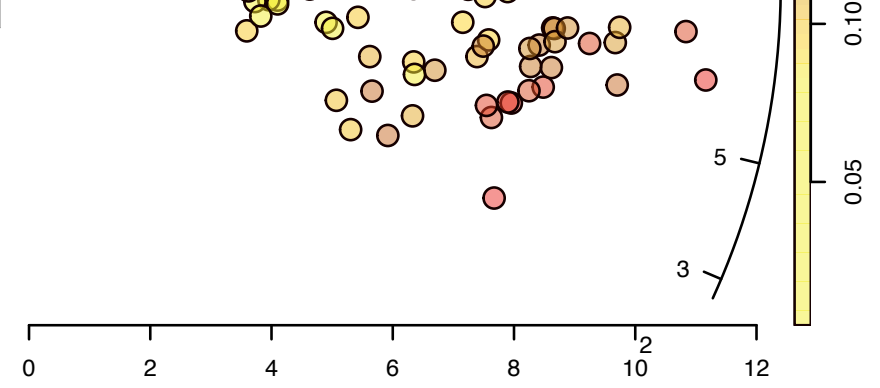

